\title{
Notes on the vocalizations of Two-banded Warbler (Basileuterus bivittatus)
}

Peter Boesman

In the following we briefly analyze and compare voice of the three races of Two-banded Warbler (Basileuterus bivittatus). We also try to quantify the extent of any vocal differences using the criteria proposed by Tobias et al. (2010), as a support for taxonomic review. We have made use of sound recordings available on-line from Xeno Canto (XC).

Our main interest is to compare the disjunct population of the tepuis (roraimae) with the Andean races. A comparison of song, illustrated with sonograms:

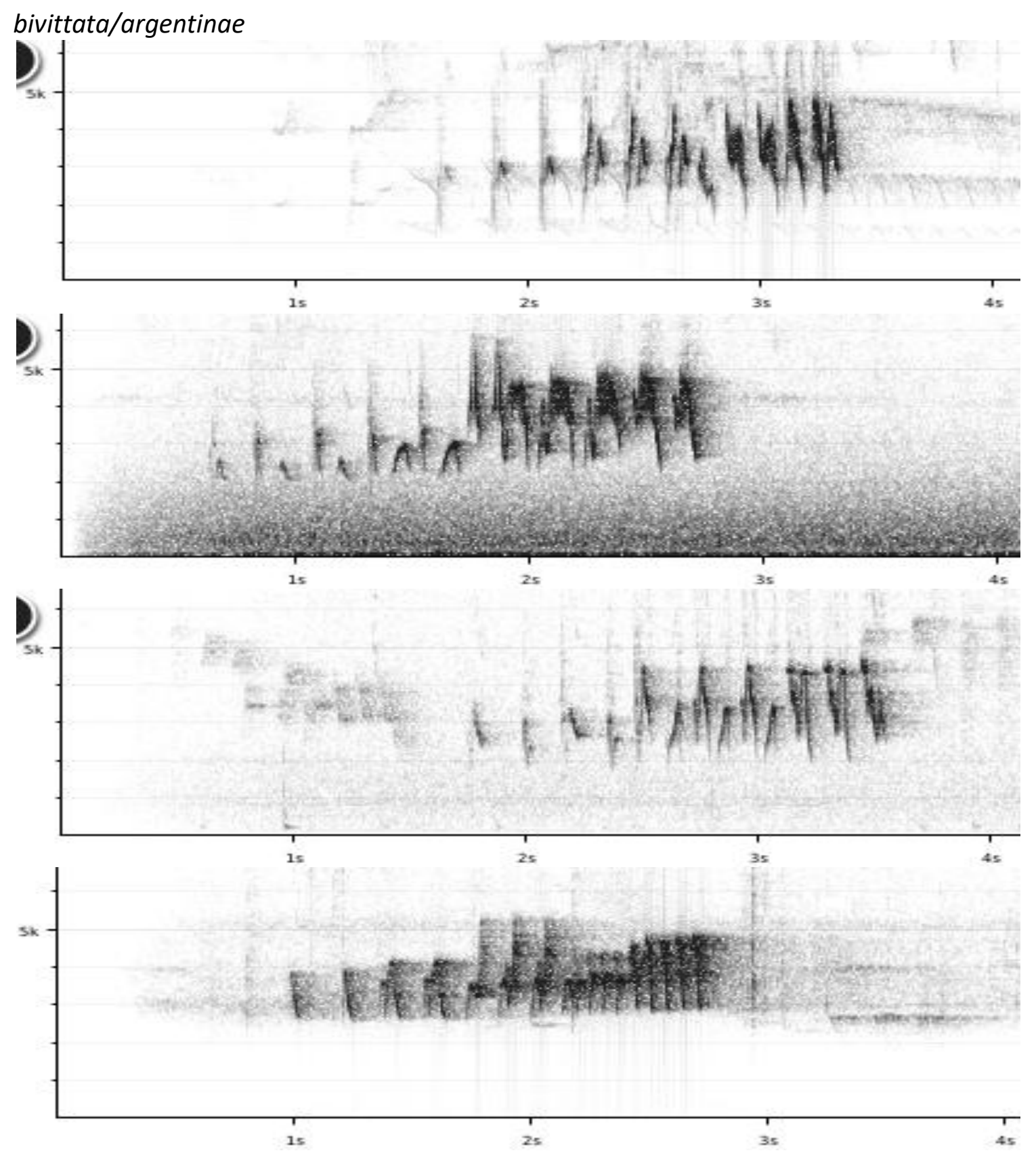




\section{HANDBOOK OF THE \\ Alve \\ ORNITHOLOGICAL NOTES}
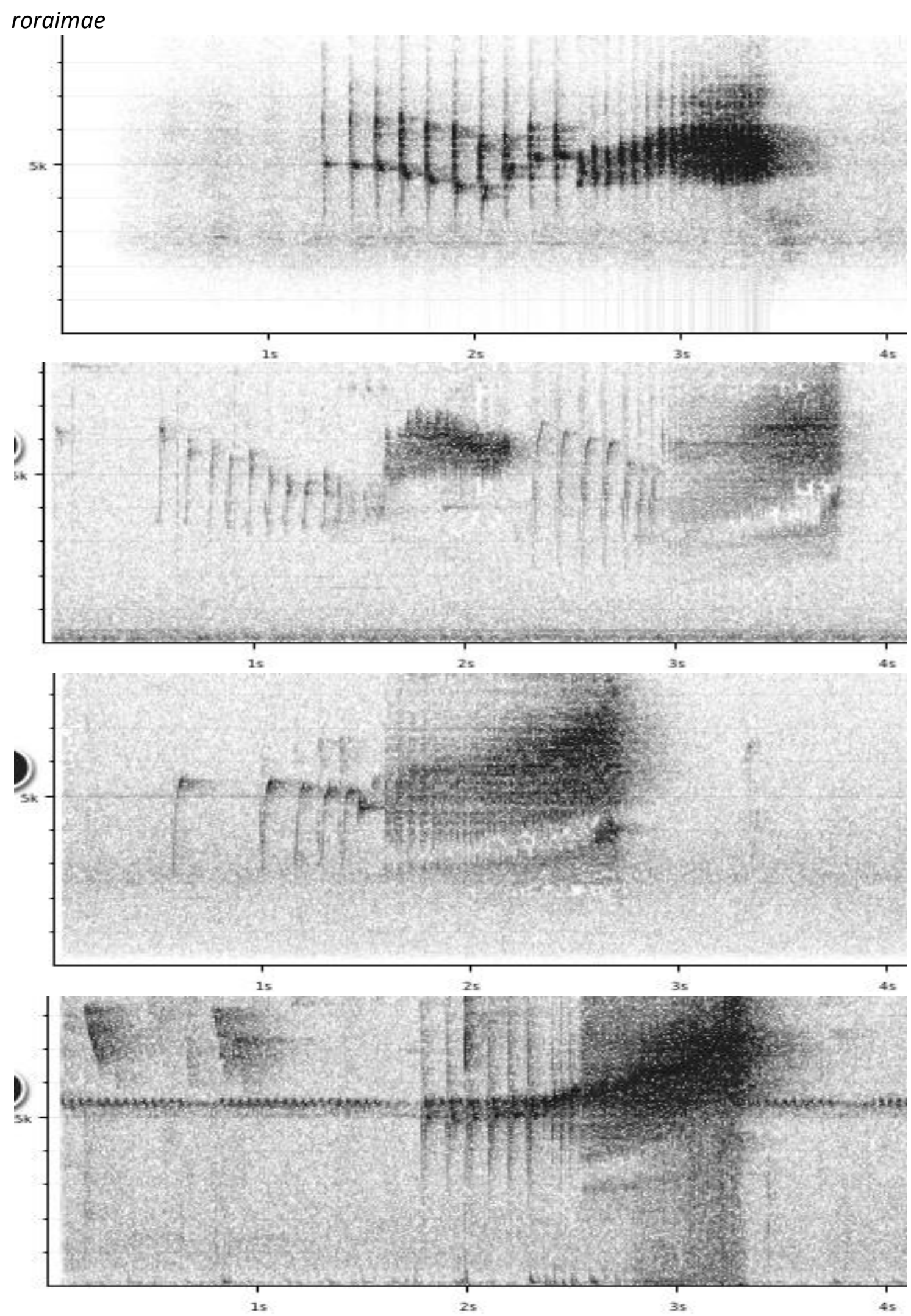

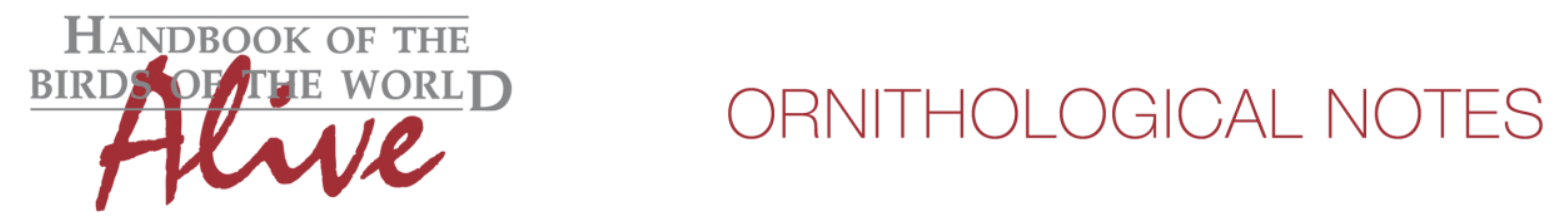

Song of both groups is clearly very different.

roraimae has a song phrase with many more notes (score 2-3), with a trilled end reaching a much higher pace (score 3-4) and reaching higher frequencies (score 2-3). Other differences are the clearly different note shapes, with roraimae having very short staccato-like notes.

Total vocal score about 6 .

roraimae seems to have 2 variants of its song: a trilled end at about same pitch, and a trilled end which is sharply rising. It is not clear whether this is given by the same bird or rather a duet performed by two birds or a coupled pair.

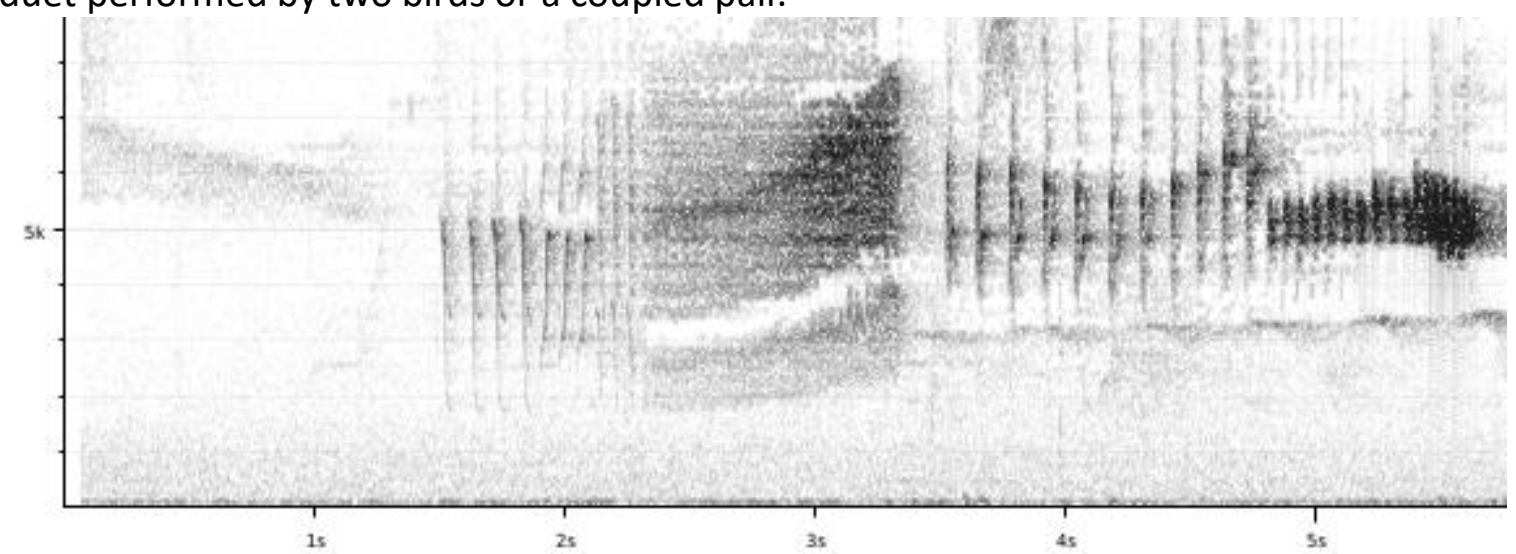

This note was finalized on 27th June 2016, using sound recordings available on-line at that moment. We would like to thank in particular the many sound recordists who placed their recordings for this species on XC.

\section{References}

Tobias, J.A., Seddon, N., Spottiswoode, C.N., Pilgrim, J.D., Fishpool, L.D.C. \& Collar, N.J. (2010). Quantitative criteria for species delimitation. Ibis 152(4): 724-746.

\section{Recommended citation}

Boesman, P. (2016). Notes on the vocalizations of Two-banded Warbler (Basileuterus bivittatus). HBW Alive Ornithological Note 376. In: Handbook of the Birds of the World Alive. Lynx Edicions, Barcelona. (retrieved from http://www.hbw.com/node/1252932 on 30 November 2016). 